\title{
Isolation of Pectin from Kesar Mango Peel Using Cation Exchange Resin
}

\author{
P. R. Davara ${ }^{*}$, M. N. Dabhi ${ }^{1}$, P. J. Rathod ${ }^{2}$, Heena Bhatu $^{1}$ \\ ${ }^{1}$ Dept. of Processing and Food Engg., College of Agril. Engg. and Technology, Junagadh Agril. University, \\ Junagadh, Gujarat, India \\ ${ }^{2}$ Dept. of Biotechnology, College of Agriculture, Junagadh Agril. University, Junagadh, Gujarat, India \\ Email: pareshdavara@yahoo.com
}

\begin{abstract}
Extraction of pectin from Kesar mango peel, a waste from mango canning and food processing industries, was carried out using cation exchange resin as an extracting medium. The effect of peel to extracting medium ratio and extraction temperature on yield and recovery of pectin was studied. Cation exchange resin was found to be the best extracting medium for extraction of pectin from mango peels. Maximum yield of pectin was obtained by taking two extractions each for one-hour duration employing a peel to extracting medium ratio of 1:4 (w:w), extraction temperature of $80{ }^{\circ} \mathrm{C}$ and at $\mathrm{pH}$ of 2.56 . Using the optimum extracting conditions, about $14.78 \%$ (DWB) of purified pectin was obtained from mango peels which gave the recovery of $96.32 \%$. The jelly grade of the pectin was found to be 170 at the optimized condition.
\end{abstract}

Keywords: Mango peel, pectin, extraction, cation exchange resin, yield

\section{Introduction}

Pectin is an important constituent present in the middle lamella of cell walls of various plant parts. Pectin plays a significant role in the manufacturing of fruit products like jams, jellies, marmalades, preserves, etc. and thus it is indispensable to the fruit processing industry. Pectin is also used as a thickening agent in the preparation of sauces, ketchups, flavored syrups and as a texturing agent in fruit flavored milk desserts. Besides, it has found numerous applications in pharmaceutical preparations, pastes, cosmetics, etc. [15].

Waste generated from citrus fruits and apple is the most important sources of pectin in the technologically advanced countries of the world. However, the availability of these raw materials in India is not enough to manufacture pectin sufficient to meet the local demand and hence a significant quantity of it is being imported from other countries every year [23]. In India, mango is the most preferred fruit to be processed into a variety of products right from immature to the ripe fruit stage. The waste generated from mango industry is in the form of peel, stones and pulper waste which is either gifted away for cattle feed or it is allowed to be decomposed in the field as manure [14]. Mango peel which contributes $12-15 \%$ of total weight of fruit is a very good source of some nutrients such as sugars, pectin, proteins and fibers. The free and plentiful availability of mango peels from mango processing units and the ease in their handling could make it a valuable source of raw material for pectin production [5].

Many methods are there for the extraction of pectin from fruit and vegetables wastes [21]. Pectin is generally extracted by suspending the fruit and vegetable wastes in different mineral acids and salt solutions [4], [22], [13]. But, still the pectin industry requires the standard method for extraction of pectin. From the available literature, it has been found that the extraction by cation exchange resin is the best for pectin extraction [16]. Double extractions at $85-88{ }^{\circ} \mathrm{C}$ for one hour using a cationic resin for the extraction of pectin from apple pomace have been reported to give higher yield and better gel strength of the product [11].

Looking into the importance of this process, it is highly essential to standardize the process of pectin extraction from mango peel by using cation exchange resin. In the present investigation, a method for extraction of pectin from Kesar mango peel under different processing conditions, viz. peel to extracting 
medium ratio, temperature and time were evaluated to obtain the good quality pectin with better yield and recovery and hence to get potential economic value of pectin.

\section{$2 \quad$ Material and Methods}

\subsection{Raw Material}

Mango peel of Kesar variety, which is extensively used by fruit processing industries in Gujarat state of India, were procured from the Mango Canning Plant of Junagadh Agricultural University, Junagadh, Gujarat (India). The peels were thoroughly washed with tap water to remove the adhered pulp and to leach out other soluble solids followed by blanching to inactivate the enzyme capable of degrading pectins and to remove pigments. The peel was then dried in the cabinet dryer at $60{ }^{\circ} \mathrm{C}$ till moisture content is reduced to $4-6 \%(\mathrm{wb})$.

In the present investigation, cation exchange resin was used as an extractin medium for pectin extraction. An ion-exchange resin is an insoluble matrix (or support structure) normally in the form of small (0.5-1 mm diameter) beads, usually white or yellowish, fabricated from an organic polymer substrate. The beads are typically porous, providing a high surface area. The use of ion exchange agents containing a -SO3H (sulphonic acid) exchange group are preferable in the pectin extraction. Resins other than the -SO3H type give comparable yields but gel grades are lower [10]. Looking to this, cation exchange resin named Indion $225 \mathrm{H}$ was used to check the feasibility of the resin in the extraction of pectin from mango peel. Indion $225 \mathrm{H}$ is a strong acid cation exchange resin containing sulphonic acid groups. This resin has high capacity and excellent kinetics. The ion-exchange capacity of Indion $225 \mathrm{H}$ resin is about $1.8 \mathrm{~mol} / \mathrm{kg}$ of dry resin [9]. The required quantity of resin was obtained from the Ion Exchange (India) Ltd., Mumbai (India).

\subsection{Extraction of Pectin Using Cation Exchange Resin}

Extraction of pectin using cation exchange resin was carried out under the following extraction conditions.

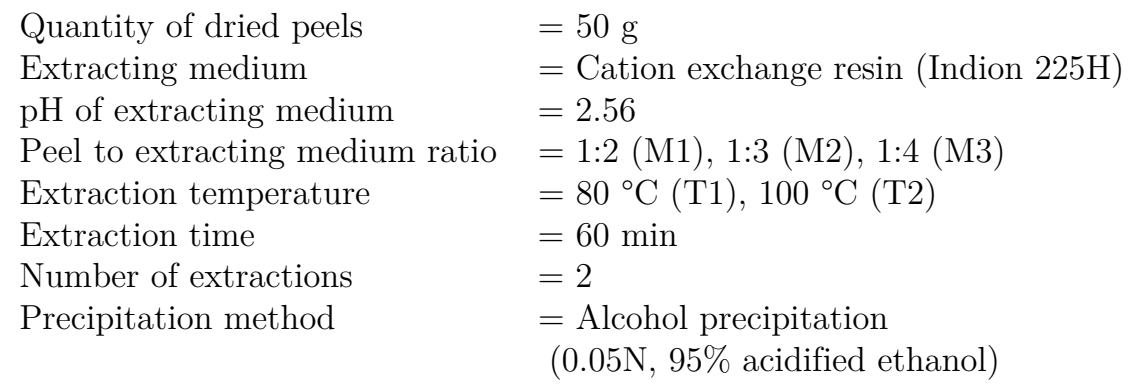

In background of the conclusions given by some of the scientists [16], [11] and [18] for better yield and quality of pectin, $\mathrm{pH}$ of 2.56 was selected for the extraction of pectin. While the extraction time (60 min) was kept constant for all the treatments in context to the recommendation given by [23], [3] and [8]. [23] indicated that all the pectin from mango peels could not be recovered in a single extraction and a second extraction was found necessary to recover most $(94.6 \%)$ of it, hence, the number of extractions was kept limited up to two. [19] and [2] also found that two extractions each for one hour were necessary to recover $92.5 \%$ and $96.0 \%$ of total pectin from guava fruits and orange peel, respectively.

\subsection{Procedure for Extraction of Pectin}

The extraction of pectin was done in accordance with the procedure suggested by [16]. The cation exchange resin was mixed with coarse grinded dried mango peel and distilled water was added to form the aqueous slurry of mango peel and resin. The amount of added water was decided on the basis of preliminary trials and kept 10 times the amount of mango peel. The mixture was continuously stirred and maintained at selected temperatures $\left(80{ }^{\circ} \mathrm{C}\right.$ and $\left.100{ }^{\circ} \mathrm{C}\right)$ for $60 \mathrm{~min}$. Concentrated $\mathrm{HCl}$ was added dropwise to maintain the $\mathrm{pH}$ of 2.56. The extract was separated using refrigerated centrifuge 
(Model:MP800, Electrocraft (India) Pvt. Ltd., Mumbai, India) at $7000 \mathrm{rpm}$ for $15 \mathrm{~min}$, strained through cheesecloth and the pectin was precipitated by the addition of three volumes of $95 \%$ ethanol containing $0.05 \mathrm{~N} \mathrm{HCl}$. The precipitated pectin was separated by simple filtration using muslin cloth and then washed at least twice with $95 \%$ ethanol containing $0.05 \mathrm{~N} \mathrm{HCl}$. Finally, the precipitate was washed with $95 \%$ ethanol without any added $\mathrm{HCl}$ and dried at $40{ }^{\circ} \mathrm{C}$ in a hot air oven and powdered. The dried pectin powder was filled in airtight polyethylene bag to avoid moisture absorption and stored at ambient temperature $\left(30-35^{\circ} \mathrm{C}\right)$. The major steps involved in the extraction of pectin from mango peels are given in Fig. 1 in the form of process flow chart.

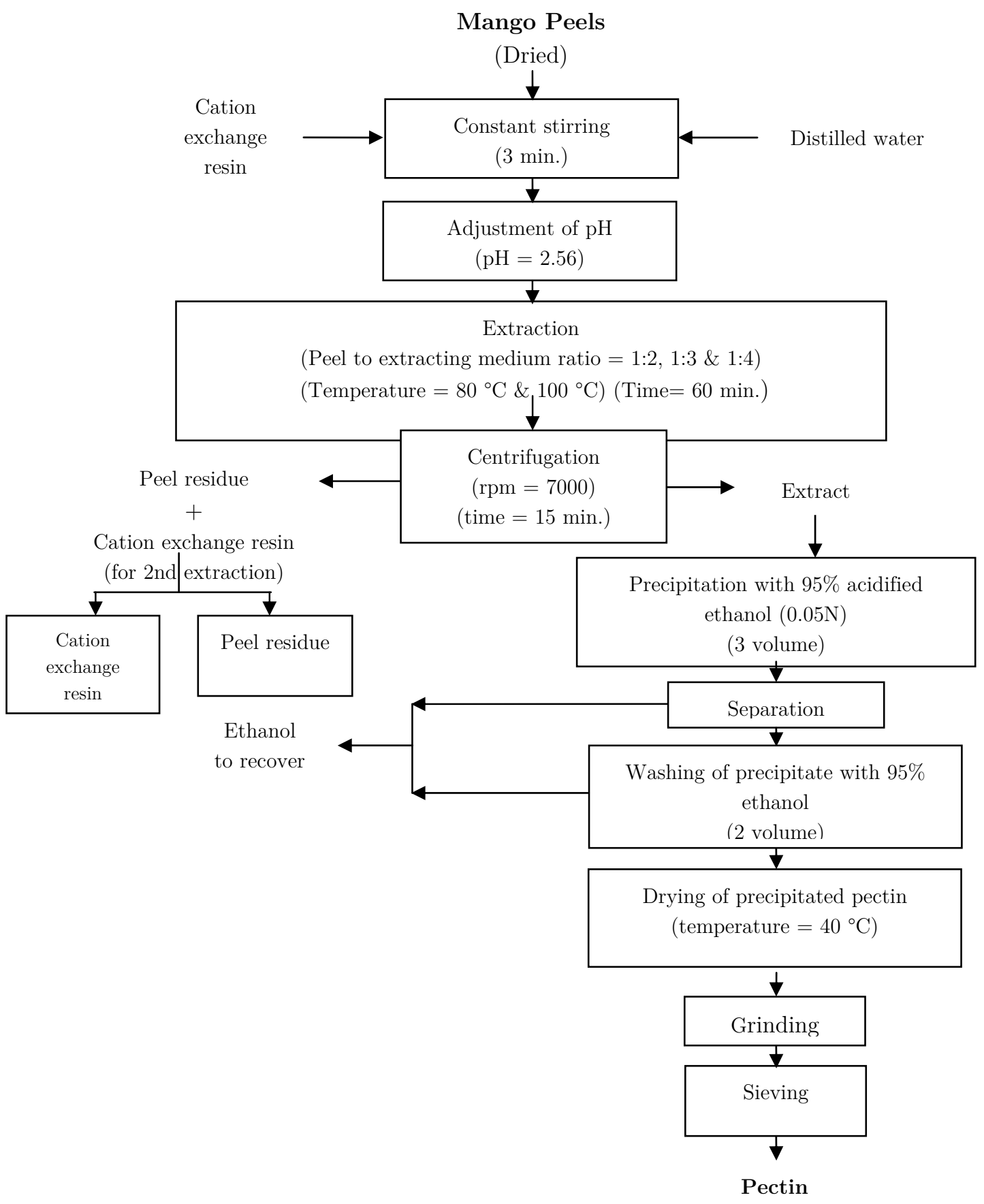

Figure 1. Experimental flow chart for extraction of pectin by cation exchange resin [16], [10], [18]. 


\subsection{Estimation of Pectin Content in Mango Peel}

To estimate the pectin content in the Kesar mango peel, the dried mango peels were coarsely grinded and $50 \mathrm{~g}$ of it was mixed with $300 \mathrm{ml}$ of $0.01 \mathrm{~N} \mathrm{HCl}$ in $1 \mathrm{~L}$ beaker and the mixture was boiled for 30 min. The residues and solution after boiling of mango peel were separated by cooling centrifuge. This procedure was repeated twice by boiling the separated residues first in $100 \mathrm{ml}$ of $0.05 \mathrm{~N} \mathrm{HCl}$ for 20 min and then in $100 \mathrm{ml}$ of $0.3 \mathrm{~N} \mathrm{HCl}$ for $10 \mathrm{~min}$. The separated solutions were cooled, pooled and volume was made up to $500 \mathrm{ml}$ by addition of water. 100 to $200 \mathrm{ml}$ of pooled solution with 250 ml water was taken into $1 \mathrm{~L}$ beaker and neutralized with $1 \mathrm{~N} \mathrm{NaOH}$. Excess $10 \mathrm{ml}$ of $1 \mathrm{~N} \mathrm{NaOH}$ was added with constant stirring and allowed it to stand for $16 \mathrm{~h}$. To the neutralized solution, $50 \mathrm{ml}$ of $1 \mathrm{~N}$ acetic acid and after $5 \mathrm{~min}, 25 \mathrm{ml}$ of $1 \mathrm{~N}$ calcium chloride were added with stirring. The solution was allowed to stand for $1 \mathrm{~h}$ and boiled for 1 to $2 \mathrm{~min}$. After boiling, the solution was filtered through a pre-weighed Whatman No.1 filter paper. The precipitated calcium pectate was washed with boiling $\left(75\right.$ to $\left.80{ }^{\circ} \mathrm{C}\right)$ water till the filtrate was free from chlorine. The filter paper with chlorine free calcium pectate was dried in a hot air oven at $100{ }^{\circ} \mathrm{C}$ till it gets constant weight (4 to $5 \mathrm{~h}$ ). The filter paper along with dried calcium pectate was cooled in desiccator and weight was measured. Percent calcium pectate was calculated by the formula as given below [20].

$$
\% \text { calcium pectate }=\frac{\text { Weight of calcium pectate } x 500 \times 100}{m l \text { of solution taken for estimation } x \text { weight of sample }}
$$

\subsection{Yield and Recovery of Pectin}

The yield of pectin was calculated in percent dry weight basis $(\% \mathrm{DWB})$ by taking the ratio of weight of pectin obtained and quantity of dried peel used in the extraction. Similarly, the recovery of pectin was determined by dividing the yield of pectin with total estimated pectin content in the dried mango peel.

\subsection{Ash Content}

Ash content is the residue remaining after destruction of organic matter. 1 to $2 \mathrm{~g}$ of pectin sample and 2 to 3 drops of ethanol were taken into pre-weighed silica crucible. The pectin and ethanol mixture was ignited slowly. Crucible with completely ignited pectin sample was placed in the electrical muffle furnace for $4 \mathrm{~h}$ at $600{ }^{\circ} \mathrm{C}$ temperature. After completion of process, the crucible was cooled to room temperature in a desiccator and weight was taken. The difference between initial weight of empty crucible and final weight of crucible with ash was taken as weight of pectin ash [20]. Percent ash content was calculated by the formula given below:

$$
\text { Percentage of ash }=\frac{\text { Weight of ash }}{\text { Weight of pectin }} \times 100
$$

\subsection{Alkalinity of Ash}

The ash obtained from $2 \mathrm{~g}$ of pectin sample was taken in $250 \mathrm{ml}$ conical flask and moistened with a little distilled water (1 to $2 \mathrm{ml}$ ). To the ash water solution, $25 \mathrm{ml}$ of $0.1 \mathrm{~N} \mathrm{H} 2 \mathrm{SO} 4$ was added and heated for $15 \mathrm{~min}$. During heating, the water loss by evaporation was avoided. After heating the solutions in the conical flask, the solutions were allowed to cool at room temperature and then titrated against $0.1 \mathrm{~N}$ $\mathrm{NaOH}$ using methyl red/methylene blue as an indicator [12]. The above process was repeated for blank preparation, i.e. without pectin ash for the preparation of solution. The percent alkalinity was estimated by the following equation:

mole Equivalent $=4(\mathrm{a}-\mathrm{b}) \mathrm{N} \mathrm{NaOH}$ per $\mathrm{kg}$ of pectin.

where,

$\mathrm{a}=$ Burette reading for blank

$\mathrm{b}=$ Burette reading for pectin ash solution

$$
\text { Percentage of alkalinity }=\frac{\text { Mole equivalent }}{10000} \times 40
$$




\subsection{Equivalent Weight}

Pectin sample of $0.5 \mathrm{~g}$ and $5 \mathrm{ml}$ ethanol was taken into the $250 \mathrm{ml}$ conical flask. $1 \mathrm{~g}$ of sodium chloride to sharpen the end point, $100 \mathrm{ml}$ of carbon dioxide free distilled water and 6 drops of phenol red indicator was added to pectin ethanol solution. The solution was shaken thoroughly till all the pectin substances were dissolved and no lumps were retained on the side of the flask. The solution was titrated slowly with $0.1 \mathrm{~N} \mathrm{NaOH}$ until the color of the indicator changed; the color change should persist at least for 30 sec. [20]. The equivalent weight of pectin was calculated according to following formula:

$$
\text { Equivalent weight }=\frac{\text { Weight of sample }}{\text { ml. of alkali } x \text { normality of alkali }} \times 40
$$

\subsection{Methoxyl Content}

Methoxyl content was determined by saponification of the pectin and titration of the librated carboxyl group $(\mathrm{COOH})$ with standard $\mathrm{NaOH}$ as per the procedure described by [20]. The neutral solution was titrated for equivalent weight; containing $0.5 \mathrm{~g}$ pectin. In the solution $25 \mathrm{ml}$ of $0.25 \mathrm{~N} \mathrm{NaOH}$ was added and was thoroughly shaken. The solution was allowed to stand for $30 \mathrm{~min}$. at room temperature. After $30 \mathrm{~min} .25 \mathrm{ml}$ of $0.25 \mathrm{~N} \mathrm{HCl}$ was added to the solution. The solution was shaken thoroughly and titrated by $0.1 \mathrm{~N} \mathrm{NaOH}$ until the color of the solution changes. Methoxyl content was calculated according to following formula:

$$
\text { Methoxyl content }=\frac{m l \text { of alkali } x \text { normality of alkali } x 3.1}{\text { Weight of sample }}
$$

\subsection{Relative Viscosity}

Ash and moisture free pectin sample of $0.5 \mathrm{~g}$ and $100 \mathrm{ml}$ distilled water was taken into $250 \mathrm{ml}$ beaker. The solution was stirred for $2 \mathrm{~h}$ till all the pectin gets dissolved in water. After $2 \mathrm{~h}, 10 \mathrm{ml}$ solution was taken in Ostwald viscometer and drawn through the capillary into a bulb up to mark A. The time (seconds) required for pectin solution to flow in Ostwald viscometer from the (mark A) neck of the bulb to the bottom mark B was measured by using stopwatch. Same way, the time required to flow $10 \mathrm{ml}$ distilled water was also measured by Ostwald viscometer. The temperature of distilled water was kept same as it was for pectin solution, i.e. room temperature. Relative viscosity was calculated according to formula suggested by [20].

$$
\text { Relative viscosity }=\frac{\text { Time is second to the } 0.5 \% \text { pectin solution to flow through }}{\text { Time is second to the distilled water to flow through }}
$$

\subsection{Jelly Grade}

Grade of pectin is the number of unit weights of sugar with one unit weight of pectin. This combination forms a satisfactory jelly under suitable conditions. The jelly grade of pectin was determined by the graph plotted between relative viscosity of one percent pectin solution and jelly grade of pectin as given by [15].

\subsection{Recovery of Resin}

The resin used in the extraction was recovered at the end of two extractions, i.e. after complete extraction procedure. Peel residue and cation exchange resin were separated simply by washing treatment. Due to lighter weight of peel residues, it was accumulated in an upper layer while resins were deposited at the bottom. The peel residues were then removed from the top by draining along with the surface water and the resin was separated. The percent cation exchange resin recovered at the end of two extractions was calculated by dividing the weight of cation exchange resin recovered after extraction with weight of cation exchange resin used in the extraction. 


\subsection{Statistical Analysis}

All the experiments in this study were replicated three times and the mean values were reported. Statistical analysis was done to study the effect of peel to extracting medium ratio (M) and extraction temperature $(\mathrm{T})$ on yield and recovery of pectin by factorial Completely Randomized Design [17].

\section{$3 \quad$ Results and Discussion}

\subsection{Pectin Content of Mango Peel}

Pectin content in dried Kesar mango peel was estimated as percent calcium pectates. The average pectin content in the dried Kesar mango peel was found to be $15.35 \%$.

\subsection{Yield of Pectin}

Graphical presentation of yield of pectin (\%DWB) in first extraction, second extraction and total of it are given in Fig. 2. From the Figure, it could be seen that the yield of pectin in first extraction was ranged from 6.68 to $8.78 \%$ (DWB) with an average yield of $7.88 \%$ (DWB). While in the second extraction, it was ranged from 4.47 to $6.00 \%$ (DWB) with an average yield of $5.36 \%$ (DWB). The total yield of pectin after two extractions was ranged from 11.15 to $14.78 \%$ (DWB) with an average total yield of pectin of $13.24 \%$ (DWB). Data showed that out of the total pectin yield, $59.52 \%$ of extractable pectin could be obtained during first extraction while the remaining $40.48 \%$ of it could be obtained during second extraction. This indicated that the pectin yield during the first extraction was higher than the second extraction by 19.04\%. However, in view of the recommendations given by [23], [19] and [2], two extractions were necessary to extract most of the pectin available in the mango peel. The maximum total yield of pectin $(14.78 \%)$ was obtained for the treatment M3T1, i.e. peel to extracting medium ratio $(1: 4)$ and temperature $\left(80^{\circ} \mathrm{C}\right)$ whereas minimum of it $(11.15 \%)$ was obtained for the treatment M1T2, i.e. peel to extracting medium ratio $(1: 2)$ and temperature $\left(100{ }^{\circ} \mathrm{C}\right)$.

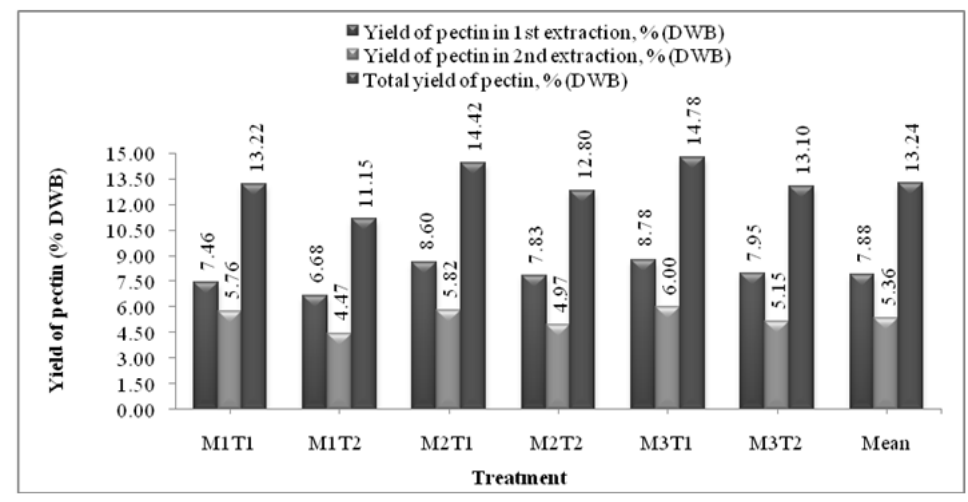

Figure 2. Yield of pectin for different treatments.

\subsection{Recovery of Pectin}

The treatment wise recovery of pectin in first extraction, second extraction and total as well as average of it is graphically represented in Figure3. 


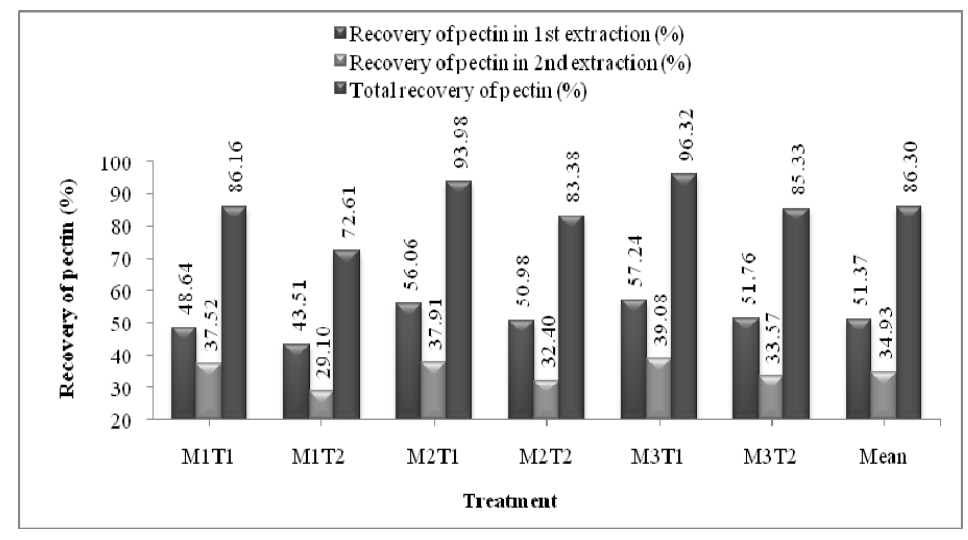

Figure 3. Recovery of pectin for different treatments.

Since the recovery of pectin was dependent on the value of yield of pectin, trend was observed similar to yield of pectin. It is evident from the Figure, that in the first extraction, the recovery of pectin was varied from 43.51 to $57.24 \%$ with an average recovery of $51.37 \%$. Whereas, it was varied from 29.10 to $39.08 \%$ with an average of $34.93 \%$, in the second extraction. The total recovery of pectin at the end of two extractions was found to be varied from 72.61 to $96.32 \%$ with an average total recovery of pectin of $86.30 \%$. From the data, it could be revealed that the proportion of recovery of extractable pectin was higher $(59.52 \%)$ during the first extraction than that of in the second extraction (40.48\%). So, from the results it could be concluded that out of the total extractable pectin, about $19.04 \%$ more pectin can be recovered during the first extraction than that of the second extraction. The similar results were obtained by [23] during the extraction of pectin from Totapuri mango peel. Pectin recovery was found maximum (96.32\%) for treatment M3T1, i.e. peel to extracting medium ratio (1:4) and temperature $\left(80{ }^{\circ} \mathrm{C}\right)$ whereas minimum $(72.61 \%)$ was found for treatment M1T2, i.e. peel to extracting medium ratio $(1: 2)$ and temperature $\left(100^{\circ} \mathrm{C}\right)$.

\subsection{Effect of Peel to Extracting Medium Ratio and Temperature on Yield of Pectin}

Extractability of pectin was found to be affected by the peel to extracting medium ratio (M) and extraction temperature $(\mathrm{T})$. The effect of peel to extracting medium ratio, i.e. 1:2 (M1), 1:3 (M2) and 1:4 (M3) and temperature, i.e. $80{ }^{\circ} \mathrm{C}(\mathrm{T} 1)$ and $100{ }^{\circ} \mathrm{C}$ (T2) on yield of pectin in first extraction, second extraction and total yield of pectin are presented in Table 1. Data revealed that the yield of pectin was linearly increased in both, first and second extraction, with an increase in the peel to extracting medium ratio from 1:2 to 1:4. As a consequence, the total yield of pectin was also increased with an increase in the peel to extracting medium ratio.

The maximum yield of pectin was obtained at peel to extracting medium ratio of $1: 4$ and the minimum of it was obtained for peel to extracting medium ratio of 1:2 in both first extraction and second extraction. These results directed to give the highest total yield of pectin for peel to extracting medium ratio of 1:4 (13.94\%DWB) and lowest yield of pectin for peel to extracting medium ratio of $1: 2$ $(12.19 \%$ DWB). This showed that with an increase of peel to extracting medium ratio from 1:2 to 1:4, the yield of pectin could be increased by $1.75 \%$. These results were in consonance with the finding of [18] who reported the increase in the yield of pectin from sunflower heads with an increase of quantity of extracting medium. Low yield of pectin at lower peel to extracting medium ratio (1:2) might be due to the insufficient quantity of extracting medium to come in contact with the pectic substances for hydrolysis and also to hold the extracted pectin [23].

Table 1. Effect of peel to extracting medium ratio $(\mathrm{M})$ and temperature $(\mathrm{T})$ on yield of pectin. 


\begin{tabular}{|c|c|c|c|}
\hline \multirow{2}{*}{ Effect } & \multicolumn{3}{|c|}{ Yield of pectin (\% DWB) } \\
\hline & 1st extraction & 2nd extraction & Total yield \\
\hline \multicolumn{4}{|c|}{ Peel to extracting medium ratio $(\mathrm{M})$} \\
\hline 1:2 (M1) & 7.07 & 5.12 & 12.19 \\
\hline 1:3 (M2) & 8.21 & 5.40 & 13.61 \\
\hline 1:4 (M3) & 8.37 & 5.57 & 13.94 \\
\hline S.Em \pm & 0.0753 & 0.1122 & 0.1693 \\
\hline $\mathrm{CD}$ at $5 \%$ & 0.2319 & 0.3459 & 0.5217 \\
\hline \multicolumn{4}{|c|}{ Extraction temperature $(\mathrm{T})$} \\
\hline $80^{\circ} \mathrm{C}(\mathrm{T} 1)$ & 8.29 & 5.86 & 14.15 \\
\hline $100{ }^{\circ} \mathrm{C}(\mathrm{T} 2)$ & 7.48 & 4.87 & 12.35 \\
\hline S.Em \pm & 0.0614 & 0.0917 & 0.1382 \\
\hline $\mathrm{CD}$ at $5 \%$ & 0.1893 & 0.2824 & 0.4260 \\
\hline \multicolumn{4}{|c|}{ Interaction $\mathrm{M} \times \mathrm{T}$} \\
\hline S.Em \pm & 0.1064 & 0.1587 & 0.2394 \\
\hline $\mathrm{CD}$ at $5 \%$ & NS & NS & NS \\
\hline C.V.\% & 2.34 & 5.13 & 3.13 \\
\hline
\end{tabular}

In case of extraction temperature, the yield of pectin decreased, in both, first and second extraction, with an increase of extraction temperature. As a consequence, the maximum yield of pectin was obtained at $80{ }^{\circ} \mathrm{C}(14.15 \% \mathrm{DWB})$ and the minimum at $100{ }^{\circ} \mathrm{C}(12.35 \%)$. Decrease in pectin yield at higher temperature $\left(100{ }^{\circ} \mathrm{C}\right)$ could be attributed due to break down of pectin molecules as already observed by [7] and [21] during the extraction of pectin from mango peel. The similar results were also reported by [1] as well as [6] during the extraction of pectin from sour orange peels and citrus fruit wastes viz. lime peel, spent guava extract, apple pomace etc., respectively.

For the yield of pectin, all three peel to extracting medium ratios $(\mathrm{M})$ and extraction temperatures $(\mathrm{T})$, their individual effects found statistically significant whereas their interaction $\mathrm{M} \times \mathrm{T}$ was showed statistically non-significant difference at $5 \%$ level of significance (Table 1).

\subsection{Effect of Peel to Extracting Medium Ratio and Temperature on Recovery of Pectin}

As the recovery was derived on the basis of yield data, the trend just similar to yield of pectin was observed in case of recovery also. It was found to be significantly affected by the peel to extracting medium ratio, i.e. $1: 2(\mathrm{M} 1), 1: 3(\mathrm{M} 2)$ and $1: 4(\mathrm{M} 3)$ and temperature, i.e. $80{ }^{\circ} \mathrm{C}(\mathrm{T} 1)$ and $100{ }^{\circ} \mathrm{C}(\mathrm{T} 2)$. The data pertains to recovery of pectin in first extraction, second extraction and total recovery of pectin are presented in Table 2 .

It is apparent from the data that there was increase in recovery of pectin in both, first and second extraction, with an increase in the peel to extracting medium ratio from 1:2 to 1:4. Due to this, the total recovery of pectin was also increased with an increase in the peel to extracting medium ratio.

The recovery of pectin, in both, first and second extraction was found to be highest at peel to extracting medium ratio of $1: 4$ and the lowest recovery was observed at peel to extracting medium ratio of 1:2. As a result of these, the recovery of pectin remained highest when extracted at peel to extracting medium ratio of 1:4 (90.83\%) and remained lowest when extracted at peel to extracting medium ratio of 1:2 (79.38\%) which showed the increase in recovery of pectin by $11.45 \%$ with an increase in peel to extracting medium ratio from 1:2 to 1:4. These results were in agreement with the findings of [18] and [23].

The extraction temperature has shown its adverse effect on the recovery of pectin. Data revealed that the recovery of pectin was declined as the temperature was increased from $80{ }^{\circ} \mathrm{C}$ to $100{ }^{\circ} \mathrm{C}$. The maximum total recovery of pectin was achieved at $80{ }^{\circ} \mathrm{C}(92.15 \%)$ and the minimum at $100{ }^{\circ} \mathrm{C}(80.44 \%)$. These results were in consonance with the results reported by [7], [21], [1] as well as [6] as explained in case of yield of pectin. The decrease in recovery of pectin with the increase in temperature had already been justified by [7], [21], [1] and [6] during the extraction pectin from various fruit waste. 
For the recovery of pectin, all three peel to extracting medium ratios $(\mathrm{M})$ and extraction temperatures (T), their individual effects found statistically significant whereas their interaction $\mathrm{M} \times \mathrm{T}$ was showed statistically non-significant difference at $5 \%$ level of significance (Table 2).

Table 2. Effect of peel to extracting medium ration (M) and temperature (T) on recovery of pectin.

\begin{tabular}{|c|c|c|c|}
\hline \multirow[t]{2}{*}{ Effect } & \multicolumn{3}{|c|}{ Recovery of pectin (\%) } \\
\hline & 1st extraction & 2nd extraction & Total recovery \\
\hline \multicolumn{4}{|c|}{ Peel to extracting medium ratio $(\mathrm{M})$} \\
\hline $1: 2(\mathrm{M} 1)$ & 46.08 & 33.30 & 79.38 \\
\hline 1:3 (M2) & 53.52 & 35.16 & 88.68 \\
\hline 1:4 (M3) & 54.50 & 36.23 & 90.83 \\
\hline S.Em \pm & 0.4898 & 0.7319 & 1.1030 \\
\hline $\mathrm{CD}$ at $5 \%$ & 1.5093 & 2.2554 & 3.3990 \\
\hline \multicolumn{4}{|c|}{ Extraction temperature $(\mathrm{T})$} \\
\hline $80{ }^{\circ} \mathrm{C}(\mathrm{T} 1)$ & 53.98 & 38.17 & 92.15 \\
\hline $100{ }^{\circ} \mathrm{C}(\mathrm{T} 2)$ & 48.75 & 31.69 & 80.44 \\
\hline S.Em \pm & 0.3999 & 0.5976 & 0.9006 \\
\hline $\mathrm{CD}$ at $5 \%$ & 1.2324 & 1.8415 & 2.7753 \\
\hline \multicolumn{4}{|c|}{ Interaction $\mathrm{M} \times \mathrm{T}$} \\
\hline S.Em \pm & 0.6927 & 1.0351 & 1.5595 \\
\hline $\mathrm{CD}$ at $5 \%$ & NS & NS & NS \\
\hline C.V.\% & 2.34 & 5.13 & 3.13 \\
\hline
\end{tabular}

\subsection{Recovery of Cation Exchange Resin}

Resin used in the extraction of pectin was recovered only after completing two extractions. Treatment wise total cation exchange resin recovered from extracted solution at the end of two extractions is graphically represented in Figure 4.

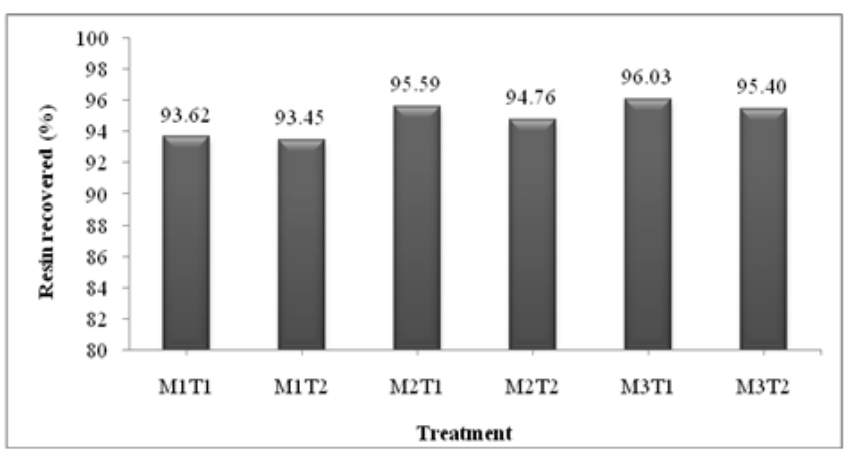

Figure 4. Recovery of cation exchange resin for different treatments.

From the figure, it could be observed that average percent recovery of cation exchange resin separated at the end of two extractions was varied from $93.45 \%$ to $96.03 \%$. The highest recovery of cation exchange resin $(96.03 \%)$ was found for the treatment, M3T1, i.e. peel to extracting medium ratio (1:4) and extraction temperature $\left(80^{\circ} \mathrm{C}\right)$ whereas the lowest recovery of it $(93.45 \%)$ for the treatment, M1T2, i.e. peel to extracting medium ratio $(1: 2)$ and extraction temperature $\left(100{ }^{\circ} \mathrm{C}\right)$. [16] also reported that 80 to $95 \%$ cation exchange resin can be recovered by centrifugal action.

\subsection{Standardization of Extracting Condition and Quality of Pectin}

The yield and recovery of pectin from mango peels at 80 and $100{ }^{\circ} \mathrm{C}$ with peel to extracting medium 
ratio of $1: 2,1: 3$ and 1:4 by cation exchange resin are discussed in above sections. From the above discussion, it was clearly noted that, yield and recovery of pectin was found better when extracted at $80{ }^{\circ} \mathrm{C}$ with peel to extracting medium ratio of $1: 4$. Hence, based on the study, the extracting conditions as given in Table 3 were standardized for extraction of pectin from mango peel by cation exchange resin. The quality parameters of the pectin extracted by standardized condition are presented in the Table 4 .

Table 3. Standardized extraction conditions for mango peel pectin by cation exchange resin.

\begin{tabular}{cc}
\hline Particulars & Extraction Condition \\
\hline Raw material & Mango peels (Variety : Kesar) \\
Extracting medium & Cation exchange resin \\
Extraction pH & 2.56 \\
Extraction temperature & $80^{\circ} \mathrm{C}$ \\
Peel to extracting medium ratio & $1: 4$ \\
Extraction time & 60 min per extraction \\
Number of extractions & 2 \\
\hline
\end{tabular}

Table 4. Quality of mango peel pectin extracted according to standardized extraction condition using cation exchange resin.

\begin{tabular}{|c|c|}
\hline Particulars & Pectin quality \\
\hline Yield of pectin (\%DWB) & $14.78 \%$ \\
\hline Recovery of pectin & $96.32 \%$ \\
\hline Ash content & $1.22 \%$ \\
\hline Alkalinity of ash & $9.85 \%$ \\
\hline Equivalent weight & 857.20 \\
\hline Methoxyl content & $3.91 \%$ \\
\hline Relative viscosity & 6.25 \\
\hline Jelly grade & 170 \\
\hline Recovery of cation exchange resin & $96.03 \%$ \\
\hline Number of extractions & 2 \\
\hline
\end{tabular}

\section{Conclusion}

The results of this study indicated that the use of cation exchange resin for extraction of pectin from mango peel exhibited the high process yield and recovery of pectin. Additionally, the pectin obtained had a good quality characteristics like especially the jelly grade, a characteristic associated with the good jelly formation of the product. Further, the resin utilized in the extraction is recoverable at the end of process and hence can be used for another extraction. Therefore, the use of cation exchange resin as an extracting medium to extract the pectin from mango peel can be an alternative to increase the yield and recovery of pectin, with good quality characteristics of the produced pectin.

\section{References}

1. Abid, H., Hussain, A., Ali, S. and Ali, J. "Technique for optimum extraction of pectin from sour orange peels and its chemical evaluation. "Journal of the Chemical Society of Pakistan, vol. 31, no. 3, pp. 459-461, 2009.

2. Agarwal, P. C. and Pruthi, J. S. "A study of factors governing the recovery and quality of pectin from fresh mandarin orange waste (peel and pomace). " Indian Food Packer, vol. 22, no. 4, pp. 5-9, 1968.

3. Attri, B. L., Maini, S. B. Extraction of pectin from Galgal (Citrus pseudolimn Tan) peel. Indian Food Packer, vol. 50, no. 2, pp. 5-12, 1996.

4. Baltaga, S. V. "Extraction of pectin from citron melon by hydrolysis with sulfurous acid. " Iyz Akad Nauk Moldavsk USSR, vol. 62, no. 6, pp. 22-25 (Chemistry Abstracts-8698,1965), 1962. 
5. Beerh, O. P., Raghuramaiah, B. and Krishnamurthy, G. V. "Utilization of mango waste: peel as a source of pectin-A research note. "Journal of Food Science and Technology, vol. 13, no. 2, pp. 96-97, 1976.

6. Chakraborty, A. and Ray, S. "Development of a process for the extraction of pectin from citrus fruit wastes viz. Lime peel, spent guava extract, apple pomace etc. " International Journal of Food Safety, vol. 13, pp. 391-397, 2011.

7. Chang, K. C., Dhurandhar, N., You, X. and Miyamoto, A. "Sunflower head residue pectin extraction as affected by physical conditions. "Journal of Food Science, vol. 59, no. 6, pp. 1207-1210, 1994.

8. Conrad, C. M. "A biochemical study of the insoluble pectic substances in vegetables." American Journal of Botany, vol. 13, pp. 531-547, 1926.

9. Gawale, R. and Marathe, K. V. "Recovery of metal ion from micellar solution. " Indian Journal of Chemical Technology, vol. 14, pp. 362-370, 2007.

10.Huang, J. M. G. "Method of extraction of pectin. " U. S. Patent 3,761,463, 1973a.

11.Huang, J. M. G. "Improved method for the extraction of pectin. "Proceedings of Florida State Horticultural Society, 86, pp. 260-261, 1973b.

12.IFU. "Determination of ash alkalinity." International Federation of Fruit Juice Producers. IFU Analysis No. 10 , 2005.

13.Jain, R. K., Ghankrokta, S. S. and Agrawal, J. D. "Isolation and characterisation of pectin from apple pomace. " Indian Food Packer, vol. 38, no. 6, pp. 65-70, 1984.

14.Kalsi, H. and Dhawan, S. S. "Potential of byproducts recovery from fruit wastes-A review. " Beverage and Food World, vol. 28, no. 5, pp. 57-62, 2001.

15.Kertesz, Z. I. "The Pectic Substance. " Wiley (Interscience). New York, p. 628, 1951.

16.Myers, P. B. and Rouse, A. H. "Extraction and recovery of pectin. " U. S. Patent 2,323,483, 1943.

17.Panse, V. G. and Sukhatme, P. V. Statistical Methods for Agricultural Workers, Fourth Editions. ICAR, New Delhi, 1985.

18.Patil, K. C. and Mishra, S. "Extraction of sunflower pectins by cation exchange resins, sodium hexa meta phosphate and oxalic acid. "Indian Food Packer, vol. 58, no. 1, pp. 78-84, 2004.

19.Pruthi, J. S., Mookerji, K. K. and Lal, G. "A study of factor affecting the recovery and quality of pectin from guava. " Indian Food Packer, vol. 14, no. 7, pp. 7-13, 1960.

20.Ranganna, S. Hand Book of Analysis and Quality Control of Fruit and Vegetable Products. Tata McGraw hill Publishing Co., Ltd., New Delhi, 1986.

21.Rehman, Z. U., Salariya, A. M., Habib, F. and Shah, W.H. "Utilization of mango peels as a source of pectin. " Journal of the Chemical Society of Pakistan, vol. 26, no. 1, pp. 73-76, 2004.

22.Srirangarajan, A. N. and Shrikhande, A. J. "Comparative aspects of pectin extracted from the peels of different varieties of mango-a technical note." Journal of Food Technology, vol. 24, pp. 539-541, 1979.

23.Sudhakar, D. V. and Maini, S.B. "Isolation and characterization of mango peel pectins. "Journal of Food Processing and Preservation, vol. 24, pp. 209-227, 2000. 